\title{
AMTEC IN 1984
}

1984 is turning into a busy year for the
AMTEC board. Members will be interested in the following birds-eye view of
upcoming and ongoing events and upcoming

- COURSES IN EDUCATIONAL TECHNOLOGY by Gar Fizzard is again available, and provides an invaluable
survey of courses offered across Canada survey of courses offered across Canad
in the field of educational technology. * COURSES IN MICROCOMPUTING IN CANADA is in production at the University of Saskatchewan. Watch for this document as an insert in an upcom ing issue of CJEC!

" MICROCOMPUTERS: A GUIDE TO PERIODICALS FOR TEACHERS, ISTS, produced for AMTEC by Ken 1STS, produce ans as "extra" with this issue of CJEC.

* The Canadian Education Association is increasing its involvement with AMTEC. The first step was a successful pr
conference workshop titled EDUCA TIONAL APPLICATIONS AND MAN preser, Larry Noonan, Clarence Landry,

Laurice Fountain, and Yvonne Husereau. ther co-sponsored

Negotiation will give AMTEC a major ray which distribution of a new award, entitled the Commonwealth Trust Award. More issue of CJEC.

AMTEC conferences continue to receive top priority. London Ontario haidoscope of media topics climaxed by a performance at Stratford of William Shakespeare's Love's Labour's Lost. AMTEC ' 85 will be held in Calgary.

CJEC is continuing to grow with more ion. Our reputation is growing. In particular the guest editor concept has inour own local coss of AMTEC outside focused attention upon other fields within which educational technology can play a Canadian studies. This issue (Vol. 13 \#2 technology to the health sciences. And other special issues are in planning stages
for the near future. Indeed, if CJEC has a

problem, it is that there is now a signifiscript, review by a busy editorial board nd final publication. To those writer cologize! But nal cannot exist without them! The majo result of the current overabundance is
that the quality of what you read is going up. At least that is our ai

. education in Canada on your behalf $\mathrm{Y}$ i too, can be actively involved in dynamic organization. Contact your loc part of our several committees. Write EC to let us know your thoughts. A sheck your membership! Don't let your colleagues be a member of AMTEC Does your school/college/university n even larger audience of education echnology professionals. We wan media to be the voice of educational in name, but in deed. Let's make 1984 can look back to!

- D.H

\section{GUEST EDITORIAL: Communication} Technologies and Health Promotion

By Dexter Harvey, Ph.D.

Health promotion has become the new with the goal of preventing illness
through the development of personal habits that are conducive to the attaineducation, health marketing, community organization and legislation are approaches frequently employed to attain the goal of health promotion The upsurge in health promotion is directly related to the growing concern to ticularly when those costs are the result of health conditions that can be prevented by adopting personal risk redurtion

habits.
Health promotion programs employ a
variety of aproaches, methods ar $r$ ? variety of approaches, methods ar. while still maintaining a person-oriented program. There is a need to develop effective approaches that will result in the public adopting behaviors conducive to
health. One area with promise is that in-

$\begin{array}{ll}\text { health. One area with promise is that in- } & \text { refer to their health information data } \\ \text { volving communication technology, } & \text { bank Tele-Health which uses the Cana- } \\ & \end{array}$ ctivities can be coordinated.
. This issue of CJEC will focus on the use in health promotion programs. In the first article David Nostbakken deals with the effectiveness of television in influencing the behaviors of children
with special reference to nonsmoking. The discussion of the influences of televion on the behaviors of children and youth is most apropos to health promo-
tion and education in general. He the describes the strengths and weaknesses of the television medium and its content for
supporting and crystallizing nonsmoking supporting and crystallizing nonsmoking
attitudes and beliefs. The article concludes with recommendations for the use examples of programs. Michel Bourque and Robert Perreault discuss the use of
computer-assisted interactive teaching as health promotion programs. As excitin describe the pedagogical issues involved
in the mediatization process of healthin the mediatization process of health-
related material for the general public. In the final article Elinor Wilson describes a community based self-help smokin
cessation program which utilizes television, radio, newspaper, community
mobilization and a printed self-manage mobilization and a printed self-manage
ment handbook. She describes a compre hensive community wide health pro ton program built as technology adva ments offer exciting new dimensions as these new advancements may be the motion is still the bottom line. The use a new technology should be based on the health and/or educational goals. edition of CJEC addresses that issue.

MEDIA NEWS

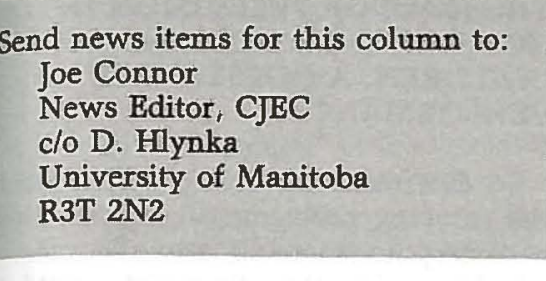

International Council for Education edia (ICEM) meeting in Canada

e next annual General Assembly an corence of the International Council ICEM provides a channel for tonal exchange of information and erience in the field of educationa echnology. The organization encourages
international liaison amongst individuals and organizations with a professional esponsibility for the design, production, romotion, distribution and use of educaonal media in member countries Manufacturers of hardware and pro-
lucers of software are advised on the need of education in member countries. ICEM promotes an understanding of educational technology both to educato and to those, involved in teacher training
and acts as an information service of developments in educational technology and provide

More than 30 member countries conribute to the pool of educational medi peration, co-production and exchange. hree subcommittees of ICEM are Prod Equipment.

e week of October 1, 1984 at the Banft entre. The General Assembly will be Ollowed by a two day Conference on icational technologies to enhance

erts in the field of distance education will make presentations, which include such topics as computer assisted cor-
espondence learning teleconferencing en learning, micro computer, ne

or further information, contact con

Hans G. Kratz

Chairman ICEM Conference

1160 Jasper Avenue, Room 32

DMONTON, Alberta

Tel: 4034274920
AMTEC Board Member completes distance education study. of the requirements for the degree document which summarizes the state the art of distance education in Canada to University of Saskatchewan

The background to the study presents review of literature on terminology and trends in distance education as well as a guishes between the implications distinguishes between the implications of pro-
gramming and delivery technologies fo distance learning.

The review of off-campus studies at the University of Saskatchewan includes both credit and non-credit course delivered during the academic year 1980-1. These programs were examine in terms of their purpose and the need for total numbers of courses, and methods delivery, course locations, costs, merits The investigation of three selected cen tres involved in distance education in versité and the Knowledge Network Athabasca and Telé-université were investigated according to their use of distance education methodology an communications technology to provide
university credit courses and the associated costs. The Knowledge Network was examind in terms of its recent development as a provincial communicatelecommunications network for carrying distance education.

The study investigated the potential of guishing that programming techndistincontribute to the creation of a messa whereas delivery technologies carry the message over distances. When program ming tech ogles are used in distance system which is conceived to serve the needs of the learner and the objectives of the course within the constraints of cost and accessibility. The potential of delivery technology is related to its infortrol features and costs. The con postulates that the costs of delivery echnology are such that the best way for educational institutions to access thes channels would be as a co-operative or

Because there is no single formula for
.

the success of a distance education program, the study concludes by providing a These options reflect future directions. national trends in distance and interdevelopments in communications technology and associated costs, but most importantly, they incorporate the needs and special circumstances surrounding offcampus learning at the University of

Logo For Atari

Atari Logo features collision detection, animation and four dynamic graphics turtles". The unique features of Atari imultaneously on one screen and multivoice sound capabilities. Joysticks and voice sound capabilities. Joysticks and Logo. programs allow beginners to mords. Such shapes on the screen the first time they The Atari Logo program cartridge works on all Atari Home Computers and plete package, includin a raM. The comand two 200-page manuals, Introduction to Programming Through Turtle Graphics and ATARI Logo Reference Manual, has a suggested retail price of peg. purchase manuals and program cartridges

\section{CJEC \\ EDITOR}

The current position of editor of the Fall 1985. So that continution expires editors is maintained, the new edito will act as associate editor for the year preceding.

The position allows the individual an opportunily to become actively involvional technology in Canada.

A search committee has been tial applicants during the London con-
ticat ference in June, 1984.

Submit references to Bill Hanson, Alynka, C.JEC editor, or to D. Education, University of Manitoba, R3T 2N2. 